\title{
Antimicrobial Activity of Secondary Metabolites of Fungi Isolated from Leaves of Bush Mango
}

Chioma Nwakanma ${ }^{1 *}$, Njoku EN ${ }^{2}$ and Pharamat $\mathrm{T}^{3}$

${ }^{1}$ Department of Environmental Management and Toxicology, Michael Okpara University of Agriculture, Umudike, Abia State, Nigeria

${ }^{2}$ Department of Biological Sciences, Godfrey Okoye University, Enugu State, Nigeria

${ }^{3}$ Faculty of Science, Chulalongkorn University, Thailand

*Corresponding author: Chioma Nwakanma, Department of Environmental Management and Toxicology, Michael Okpara University of Agriculture, Umudike, Abia State, Nigeria, Tel: +08032017146; E-mail: dr.nwakanmac@gmail.com

Rec date: Aug 23, 2016; Acc date: Oct 04, 2016; Pub date: Oct 06, 2016

Copyright: (c) 2016 Nwakanma C, et al. This is an open-access article distributed under the terms of the Creative Commons Attribution License, which permits unrestricted use, distribution, and reproduction in any medium, provided the original author and source are credited.

\begin{abstract}
Antimicrobial activity of secondary metabolites of fungi isolated from leaves of Bush mango against some selected microorganisms (Escherichia coli, Staphylococcus aureus, Pseudomonas aeruginosa, Bacillus subtilis, Penicillium chrysogenum and Aspergillus fumigates) was carried out in this study. Agar well diffusion method was used to study the antimicrobial activity of the secondary metabolites and each of the secondary metabolites showed antagonist activity against the test organisms; two gram positive bacteria (Staphylococcus aureus and Bacillus subtilis), two gram negative bacteria (Escherichia coli and Pseudomonas aeruginosa) and two fungi (Penicillium chrysogenum and Aspergillus fumigatus). Findings from the research indicates that the studies could also pave a way for new therapeutic agents which can be used as potential drugs against the selected microorganisms or its infections.
\end{abstract}

Keywords: Endophytes; Ecology; Antioxidants; Microorganisms; Metabolites

\section{Introduction}

Cancers and various infectious diseases threaten worldwide human health $[1,2]$. Endophytes are microorganisms that live in the intercellular spaces of healthy host tissues without causing obvious symptoms. Bioprospecting studies of endophytic microorganisms for pharmaceutical and biotechnological purposes are fundamental for the discovery of new substances for human therapeutics including antibiotics, anti-malarials, and anticancer [3-5]. Microorganisms are important sources of bioactive natural products with enormous potential for the discovery of new molecules for drug discovery, industrial use and agricultural applications [6-10]. In comparison to other natural sources like plants, microorganisms are highly diverse but narrowly explored. Studies based on estimation of microbial populations have revealed that only about $1 \%$ of bacteria and $5 \%$ of fungi have been characterized and the rest remain unexplored for their contribution to the human welfare. In addition, more than $60 \%$ of the anticancer and $70 \%$ of the antimicrobial drugs currently in clinical use are natural products or natural product derivatives [11].

A study of the World Health Organization (WHO) revealed that $90 \%$ of the bacteria strains are resistant to drugs of first choice. Examples of the resistance problems on a global scale are the methicillin resistant Staphylococcus aureus (MRSA), vancomycin resistant Enterococci and Enterobacteriaceae producing betalactamases. Drug resistance in bacteria has become a global concern and the search for new antibacterial agents is urgent and ongoing [12]. The abuse and overuse of drugs especially antibiotics and antimicrobials contributes to microbial drug resistance. Fox television sent a 26-year-old assistant producer to four doctors' offices in Denver,
Colorado, claiming that she did not feel well. Four out of four doctors prescribed an antibiotic.

Endophytes, microorganism that reside in the tissue of living plants, are relatively understudied and potential source of novel natural products for exploitation in medicine, agriculture and industries [13]. The resistance of pathogenic microorganisms to drugs and antibiotics has become a major challenge in the health sector leading to reduction in drug effectiveness and economic wastage. This challenge has once again stirred up a need in scientific research and the discovery of new more effective antimicrobial metabolites becoming a major research interest. In Recent years, the isolation of endophytic fungi and screening of antimicrobial activity has gained more attention [3].

\begin{tabular}{|l|l|l|l|}
\hline $\begin{array}{l}\text { Endophytic fungal } \\
\text { isolates }\end{array}$ & $\begin{array}{l}\text { Initial weights } \\
\text { of flasks (gram) }\end{array}$ & $\begin{array}{l}\text { Final weight of } \\
\text { flasks (gram) }\end{array}$ & $\begin{array}{l}\text { Weight } \\
\text { secondary } \\
\text { metabolite (gram) }\end{array}$ \\
\hline EDF1 & 157.26 & 158.673 & 1.413 \\
\hline EDF2 & 191.24 & 192.5 & 1.26 \\
\hline EDF3 & 166.101 & 167.331 & 1.23 \\
\hline EDF4 & 162.91 & 164.85 & 1.94 \\
\hline EDF5 & 161.162 & 162.682 & 1.52 \\
\hline Key: EDF= Endophytic fungi & & \\
\hline
\end{tabular}

Table 1: Weight of secondary metabolite extracted.

The increase in the resistance of drugs by infectious pathogens as well as undesirable effects of certain antimicrobial agents indicates that there is an urgent need for novel and effective bioactive compounds with fresh modes of action which is what this study is aimed at 
achieving stated that during the last 20 years $[9,10]$. It has been observed that much of the wealth of microbial biodiversity with novel biochemistry and secondary metabolite production resides in plant tissues.

This increased the interest in such microorganisms, termed as endophytes, with the discovery of an endophytic fungus, from Taxus brevifolia, producing the billion-dollar anti-cancer drug, taxol [14]. Endophytes are metabolically more active than their free counterparts due to their specific functions in nature and activation of various metabolic pathways to survive in the host tissues $[5,9,15]$. However, the sequencing of the taxadiene synthase gene from the taxol producing endophyte revealed that endophytes possess biosynthetic pathways independent of the plant host [16]. This implies that microorganisms have much more biosynthetic proficiency than previously thought. Thus, microorganisms may be screened for a wide range of biological activities and explored for useful chemical entities consistently produced by them. The discovery of novel anti-microbial metabolites from endophyte is an important alternative to overcome the increasing levels of drug resistance by plants and human pathogens [17]. The microbial resources of green plants particularly the endophytic populations remain completely unexplored. Thus, an investigation is carried out to isolate and characterize the endophytic microorganisms form bush mango leaves (Irvingia gabonensis) and explore their bioactive potential and also isolate new leads which will assist in drug discovery, industrial and agriculture improvement.

Irvingia gabonensis is a species of African trees in the genus Irvingia. A research by showed that the possess medicinal properties including antimicrobial effects against Escherichia coli and Staphylococcus aureus [18]. He also reported that the plant showed antioxidant activity [19].
Leaf and root extracts have documented inhibitory activity against several bacteria and fungi [20,21]. In Cameroon, preparation mainly from the bark are used to treat hernia and yellow fever and as an antidote for poisoning and kernels of Irviginia gabonensis are used to treat diabetes [18]. According to preparations from the bark are rubbed on to the body to relieve pains and are applied to sores and wound and against toothache and they are also taken to treat diarrhea [22]. In their research reported that the potential mechanism of action includes membrane disruption by terpenoids and inactivation of microbial adhesion, enzymes and cell envelope transport proteins by ellagic acid-like compounds [21].

\section{Materials and Methods}

The plants were collected with tweezers, hand gloves, plastic bags and containers from a field outing and survey plan. The rational selection of host plant is crucial to increase the chances of isolation of novel microorganisms which may produce new bioactive compounds [23]. Therefore, it is necessary to understand the methods and rationale used to provide the best opportunities to isolate novel endophytic microorganisms as well as ones making novel bioactive products.

The plant sample was identified and authenticated by a taxonomist in the department of botany University of Nigeria Nsukka, Enugu state, Nigeria. The study area was Amorji-Nike village in Enugu-East local government area of Enugu State, Nigeria. The convenient sampling technique used was simple random selection method. This was used in order to give the different plant leaves an opportunity to represent therapeutic values of the plant vegetation within the geographical locations of the study area.

\begin{tabular}{|l|l|l|l|l|l|l|}
\hline \multirow{2}{*}{$\begin{array}{l}\text { Endophytic } \\
\text { isolates }\end{array}$} & fungal & Inhibition zone $(\mathbf{m m})$ (mean \pm SD) \\
\cline { 2 - 7 } & EC & SA & BS & PA & AF & PC \\
\hline EDF1 & $9.50 \pm 0.50$ & $8.50 \pm 1.50$ & $13.50 \pm 1.50$ & $3.50 \pm 0.50$ & $10.50 \pm 0.50$ & $4.50 \pm 0.50$ \\
\hline EDF2 & $0.00 \pm 0.00$ & $3.00 \pm 1.00$ & $12.00 \pm 2.00$ & $9.00 \pm 1.00$ & $9.50 \pm 0.5$ & $11.50 \pm 0.50$ \\
\hline EDF3 & $2.00 \pm 1.00$ & $2.50 \pm 0.50$ & $0.00 \pm 0.00$ & $2.50 \pm 0.50$ & $9.50 \pm 0.50$ & $7.50 \pm 1.50$ \\
\hline EDF4 & $3.00 \pm 1.00$ & $3.50 \pm 0.50$ & $0.00 \pm 0.00$ & $1.50 \pm 0.50$ & $11.50 \pm 0.50$ & $10.50 \pm 0.50$ \\
\hline EDF5 & $1.50 \pm 0.50$ & $2.50 \pm 0.50$ & $4.00 \pm 1.00$ & $3.00 \pm 1.00$ & $13.00 \pm 2.00$ & $16.50 \pm 2.50$ \\
\hline Ciprofloxacin & $7.00 \pm 0.00$ & $5.50 \pm 0.50$ & $15.00 \pm 0.00$ & $12.50 \pm 0.50$ & - & - \\
\hline Fluconazole & - & - & - & - & $17.50 \pm 0.50$ & $15.50 \pm 0.50$ \\
\hline Water & - & - & - & - & - \\
\hline Keys: BS=B. subtilis, SA=S. aureus, EC=E. coli, PA=P. aeruginosa, PC=P. chrysogenum DF=Endophytic fungi and AF=A. fumigatus
\end{tabular}

Table 2: Inhibition diameters $(\mathrm{mm}) \pm$ Standard error.

The population of this study identified about sixteen different colonies of the endophytic fungi. To determine the sample size of the study, five distinct colonies based on morphological observation were selected by the researcher to form a $31.25 \%$ ratio of the population of the study. Sample collection were done through the help of a highly renowned herbal products specialists and a plant specialist to acquire information and also help in identifying the plants. For preparation of the potato dextrose agar, the laboratory bench was cleaned with cotton wool soaked in ethanol, this is done to avoid contamination and enhance aseptic conditions. $3.9 \mathrm{~g}$ of potato dextrose agar powder was weighed into a $250 \mathrm{ml}$ conical flask and then dissolved with $150 \mathrm{ml}$ of distilled. The media was homogenized by agitating and then sterilized by autoclaving at $121^{\circ} \mathrm{C}$ for 15 minutes, after which it was aseptically poured into sterile Petri dishes and allowed to gel. Also, preparation of nutrient broth, sabour and dextrose agar and Mueller Hinton agar was 
also carried out in the laboratory. For isolation of endophytic fungi, the leaves were washed under running tap water for 10 minutes.

The leaves were cut into small pieces and sterilize in series with sterile distilled water for 1 minute, $70 \%$ ethanol for 1 minute, $1.0 \%$ sodium hypochlorite $(\mathrm{NaOCl})$ for 2 minutes and further cleaned by passing through two sets of sterile distilled water for 5 minutes and allowed to surface dry under sterile conditions. The sterile samples were placed on the surface of potato dextrose agar (PDA) plates supplemented with $1 \mathrm{~g} / \mathrm{ml}$ of streptomycin to suppress bacterial growth and contamination.

The parafilm wrapped Petri dishes were incubated at $25^{\circ} \mathrm{C} \pm 2^{\circ} \mathrm{C}$ till the fungal mycelia starts growing from the samples. When the growth started, a pure culture of a particular endophytic fungi was isolated and inoculated on a fresh media. Solid state fermentation was carried out using the following procedures: $100 \mathrm{~g}$ of rice and $200 \mathrm{ml}$ of water were poured in $1000 \mathrm{ml}$ conical flask and then autoclaved at $121^{\circ} \mathrm{C}$ at 15 psi for 1 hour and allowed to cool. $3 \mathrm{~mm}$ diameter agar blocks containing the test fungi was inoculated in the conical flask containing the already autoclaved rice and it was incubated at $25^{\circ} \mathrm{C}$ to $27^{\circ} \mathrm{C}$ for 21 days. After the 21 days of incubation, the secondary metabolite was extracted using ethyl acetate. $500 \mathrm{ml}$ of ethyl acetate was poured into the conical flask containing the fermented rice and endophytic fungi. A glass rod was used to break the clumps formed during the incubation and it was left to stand for 24 hours. After 24 hours, it was filtered with mushlin cloth into a beaker of known weight.

The ethyl acetate filtrate in the beaker was allowed to air dry. After air drying, the crude extract residue was then dissolved in dimethyl sulfoxide (DMSO) and stored at $4^{\circ} \mathrm{C}$ and used as stock solution for antimicrobial assay and phytochemical analysis. The test organisms used were obtained from the microbiology laboratory section and mycology laboratory section of the University of Nigeria Teaching Hospital Ituku-ozala, Enugu State, Nigeria. The test organism used were six and they include two gram positive bacteria (Staphylococcus aureus and Bacillus subtilis), two gram negative bacteria (Pseudomonas aeruginosa and Escherichia coli) and two fungi Aspergillus and Penicillium. The agar well diffusion method described by with modification was used to evaluate the antimicrobial and antifungal activity against the test microorganisms [24].

The test organisms were spread aseptically using a cotton swab on the surface of the already prepared Mueller Hinton agar for the bacteria and the fungi was aseptically inoculated on the already prepared Sabouraud dextrose agar. All culture plates were allowed to dry for about five (5) minutes and four wells were made on the agar using a $6 \mathrm{~mm}$ sterile cork borer. Two wells were filled with $200 \mu \mathrm{l}$ of $100 \mathrm{mg} / \mathrm{ml}$ concentration of the extract, other well was filled with 200 $\mu \mathrm{l}$ of $50 \mathrm{mg} / \mathrm{ml}$ concentration of the positive control and the last well was filled with $200 \mu \mathrm{l}$ of the negative control. The plates were kept on the work bench to allow the agents diffuse into the agar and incubated accordingly. Ciprofloxacin and fluconazole were used as the positive controls for the antibacterial and antifungal evaluation respectively while distilled water was used as the negative control. The Mueller Hinton agar plates were incubated at $37^{\circ} \mathrm{C}$ for twenty-four (24) hours and the Sabouraud dextrose agar plates were incubated at $27^{\circ} \mathrm{C}$ for two (2) days. The antimicrobial activities were evaluated by measuring the diameter of the inhibition zones in millimeters and the readings were recorded. The experiment was replicated twice and an average of two independent reading for each microorganism was used. The antimicrobial activities were evaluated by measuring the diameter of the inhibition zones in millimeters and the readings were recorded.
The experiment was replicated twice and an average of two independent reading for each microorganism was used.

\section{Results}

A total of sixteen distinct colonies of the endophytic fungi were isolated from healthy leaves of Irvingia gabonensis. Each of the isolated sixteen distinct colonies were subcultured into potato dextrose agar plates. From the sixteen distinct colonies of the endophytic fungi subcultured, five of the isolates $(31.25 \%)$ were fermented and their extracts were used for antimicrobial assay. The weight of the secondary metabolites produced and extracted from the endophytic fungi after the 21 days of fermentation is shown in Table 1. From the table, it can be observed that the endophytic fungi in extract EDF4 produced more secondary metabolites than others while the endophytic fungi in extract EDF3 produced the least amount of secondary metabolite as shown below (Table 1).

The antimicrobial activities of crude extract of the secondary metabolite isolated from the endophytic fungi showed a board spectrum and effective antibacterial and antifungal activity.

The crude extracts of five endophytic fungi exhibited a wide variety of antimicrobial activities against six tested microorganisms. Each of the endophytic fungi produced bioactive compounds that exhibited antimicrobial activity against at least one test microorganisms used (Table 2).

\section{Discussion}

The antimicrobial activity of the crude ethyl acetate extract of the secondary metabolite isolated from different fungi were evaluated with the aim of discovering novel bioactive compounds of biomedical importance. Previous studies have shown that several extracts from endophytic fungi exhibited antimicrobial activity [24]. Endophytic fungal species are now considered as exciting novel sources for obtaining new bioactive compounds and have been reported from several hosts [25-27]. Five of the endophytic fungi isolated from leaves of Irvingia gabonensis have significantly inhibited and showed antagonist activities against the representative gram positive bacteria, gram negative bacteria and filamentous fungi.

This results correlated with the findings of other reports where they reported the antimicrobial activity of endophytes [26-31]. 16 out of 203 endophytic isolates showed antimicrobial activity with a wider action spectrum inhibiting gram-positive and gram-negative and fungi [32]. In their research also reported that 5 out of 21 isolates showed broad antagonistic activity against the all the test organisms [33]. Some of the zones of inhibition by these endophytic fungi are very much comparable to the standard antibiotics. It has been reported that Pseudomonas aeruginosa have developed drug resistance towards many antibiotics [34]. In this study all the five isolates inhibited Pseudomonas aeruginosa, with extract EDF2 showing the highest inhibition zone diameter of $9 \mathrm{~mm}$. Other extracts also showed a wide variety of antimicrobial activity on the bacteria test organisms. EDF1 exhibited antimicrobial effect against all the test organisms used. The maximum zone of inhibition recorded was $13.5 \mathrm{~mm}$ against Bacillus subtilis. EDF2 was found to be active against all test organisms except on Escherichia coli. The maximum zone inhibition was $12 \mathrm{~mm}$ (Figure 1).

The effect of the endophytic fungal extract on EDF1 and EDF2 is comparable to the antibacterial standard ciprofloxacin which showed 
Citation: Nwakanma C, Njoku EN, Pharamat T (2016) Antimicrobial Activity of Secondary Metabolites of Fungi Isolated from Leaves of Bush Mango. Next Generat Sequenc \& Applic 3: 135. doi:10.4172/2469-9853.1000135

Page 4 of 6

an inhibition zone diameter of $15 \mathrm{~mm}$. Bacillus subtilis was resistant to extracts of EDF3 and EDF4 while they showed their antimicrobial effect against the other five test organisms used. $9.5 \mathrm{~mm}$ and $11.5 \mathrm{~mm}$ respectively were the highest inhibition zone diameter recorded from the antimicrobial activity of the two extracts aforementioned and it was against a filamentous fungus Aspergillus fumigatus.

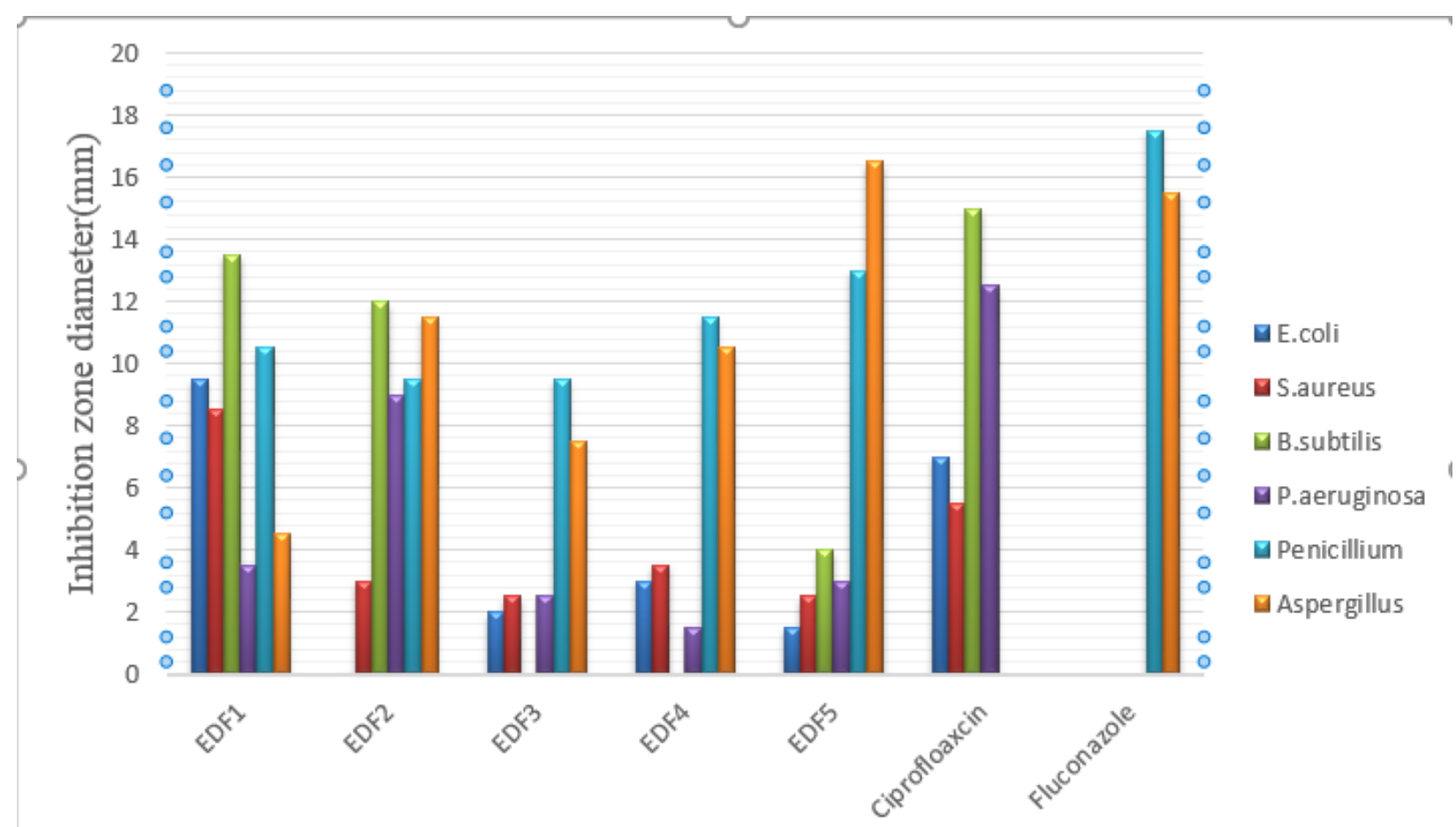

Fungal isolates and controls

Figure 1: Antimicrobial activity of the secondary metabolites extracted from the fungi.

EDF5 showed a wide range of antimicrobial activity against all the test organisms used. The highest inhibition zone diameter of $16.5 \mathrm{~mm}$ was recorded against Penicillum chysorgenum, which is comparable to the inhibition by the antifungal standard Fluconazole $(15.5 \mathrm{~mm})$. This result corresponds with the reported research results from different individuals. According to several preliminary studies have been reported on screening of endophytic fungi from medicinal plants for production of antimicrobial activities found that more than $50 \%$ of isolates displayed antimicrobial activity against at least one tested microorganisms.

They also reported that $56 \%$ of endophytic fungi from Dracaena cambodiana (Agavaceae) inhibited growth of at least one of the test organisms and $8 \%$ showed broad spectrum inhibition [35]. Crude extracts of nine endophytic fungi (75\%) isolated from Adenocalymma alliaceum Miers showed antibacterial potential against one or more clinical human pathogen [36]. Similarly, reported that the compound Nectriapyrone isolated from the endophytic fungi Colletotrichum gloeosporioides and Glomerella cingulate showed a strong antimicrobial activity against Staphylococcus aureus, Escherichia coli, Candida albicans, Trypanosoma cruzi, Leishmania tarentllae and Human T leukemia cell. Also, the isolated twelve endophytic fungi from the healthy leaves of Madhuca longifolia $L$. for antimicrobial activity [37]. They reported that the ethyl acetate extract of Colletotrichum gloeosporioides had an effective antimicrobial activity against Staphylococcus aureus, Escherichia coli and Candida albicans.
The fungal test organisms (Aspergillus fumigatus and Penicillum chysorgenum) were the most susceptible to the compounds produced by all five endophytic fungal isolates.

The maximum zone of inhibition by the endophytic fungal isolates for Aspergillus fumigatus was $13 \mathrm{~mm}$ diameter, which is comparable to the inhibition by the antifungal standard Fluconazole $(17.5 \mathrm{~mm})$. Also for Penicillum chysorgenum the maximum inhibition zone diameter was $16.5 \mathrm{~mm}$ which is also comparable to antifungal standard fluconazole $(15.5 \mathrm{~mm})$. The extract EDF1 showed the highest level of inhibition against a gram positive bacteria (Bacillus subtilis) and it also showed the highest level of inhibition against a gram negative bacteria (Escherichia coli). According to the difference in the in vitro activity among the various crude extracts could be due to the production of either a broad spectrum antimicrobial compound, or several compounds with different activities [38]. In their research explained that differences in level of inhibition by the endophytic fungi could be due to the expected different modes of action, the level of isolate inoculation and activity of the individual biochemical constituent of the respective isolates [39]. Also in his research concluded that the differences in levels of antagonism are dependent on concentration of the active substance [40].

These active endophytic fungi might be the future for antibiotics production. From this study, it was discovered that these five endophytic fungal isolates exhibited at least five of the test microorganisms used including a filamentous fungi Penicillium 
chrysogenum which is interesting because according to a research by they reported the all the six endophytic fungal isolates from Tulsi inhibited all the test organisms except Penicillium chrysogenum [41]. The present study leads to the need of further in depth studies on these isolated bioactive endophytic fungal isolates. Many are able to produce quite a good amount of antimicrobial compounds tested in preliminary test. Further growing those in large scale, modifying culture conditions like changing $\mathrm{pH}$, changing growth media and supplying some stimulants might help in getting better production of the particular bioactive compound and enzyme [42]. Furthermore, the best proved active isolates should be identified using available methods to place these fungi in the fungal kingdom. In conclusion, further investigation may yield novel compounds with practical applications in a variety of biotechnological areas, with countless useful drugs as important therapeutics options for innumerable disease.

\section{References}

1. Guo B, Wang Y, Sun X, Tang K (2008) Bioactive natural products from endophytes: A review. Appl Biochem Microbiol 44: 136-142.

2. Wang FW, Jiao RH, Cheng AB, Tan SH, Song YC (2007) Antimicrobial potentials of endophytic fungi residing in quercus variabilis and brefeldin a obtained from cladosporium sp. World J Microbiol Biotechnol 23: 79-83.

3. Strobel GA (2003) Endophytes as sources of bioactive products. Microb Infect 5: 535-544.

4. Strobel GA (2002) Rainforest endophytes and bioactive products. Crit Rev Biotechnol 22: 315-333.

5. Strobel G, Daisy BH (2003) Bioprospecting for microbial endophytes and their natural products. Microbiol Mole Biol Rev 67: 491-502.

6. Kodzius R, Gojobori T (2015) Marine metagenomics as a source for bioprospecting. Mar Genomics 24: 21 -30.

7. Demain AL (1999) Pharmaceutically active secondary metabolites of microorganisms. Appl Microbiol Biotechnol 52: 455-463.

8. Keller NP (2004) Fungal secondary metabolism from biochemistry to genomics. Nat Rev Microbiol 3: 937-947.

9. Strobel G (2006) Harnessing endophytes for industrial microbiology. Curr Opin Microbiol 9: 240-244.

10. Porras-Alfaro A, Bayman P (2011) Hidden fungi, emergent properties endophytes and microbiomes. Annu Rev Phytopathol 49: 291-315.

11. McAlpine JB, Bachmann BO, Piraee M, Tremblay S, Alarco AM, et al. (2005) Microbial genomics as a guide to drug discovery, structural elucidation: ECO02301, a novel antifungal agent, as an example. J Nat Prod 68: 493-496.

12. Liang H, Xing Y, Chen J, Guo S, Wand C (2012) BMC complementary and alternative medicine. 12: 238.

13. Sandhu SS, Rajak RC, Shukla H, Aharwal PR, Kumar S (2014) Endophytic fungi: As a source of antimicrobials bioactive compounds. J Pharm Pharm Sci 3: 1179-1197.

14. Stierle A, Strobel G, Stierle D (1993) Taxol and taxane production by taxomyces andreanae, an endophytic fungus of pacific yew. Science 260: 214-216.

15. Riyaz-Ul-Hassan S, Strobel GA, Booth E, Knighton B, Floerchinger C, et al. (2012) Modulation of volatile organic compound formation in the Mycodiesel producing endophyte- Hypoxylon sp. C1-4. Microbiology 158: 464-473.

16. Staniek A, Woerdenbag HJ, Kayser O (2009) Taxomyces andreanae: A presumed paclitaxel producer demystified? Planta Med 75: 1561-1566.

17. pongcharoen $\mathrm{W}$, rukachaisirikul V, phongpaichit S (2008) metabolites from the endophytic fungus xylaria sp. PSU-D14. Phytochem 69: 1900-1902.

18. Nworie O, Orji JO, Ekuma UO, Agah MV, Okoli CS, et al. (2016) Antibacterial activity of the leaf and stem bark of irvingia gabonensis (bush mango) against escherichia coli and staphylococcus aureus. Global J Pharmacol 10: 13-18.

19. Boakye AA, Wireko-Manu FD, Agbenorhevi JK, Oduro I (2015) Antioxidant activity, total phenols and phytochemical constituents of four underutilised tropical fruits. Int Food Res J 22: 262-268.

20. Fadare DA, Ajaiyeoba EO (2008) "Phytochemical and antimicrobial activities of the wild mango-irvingiagabonesis extracts and fraction". Africa J Med Sci 37: 119-124.

21. Kuete V, Wabo GF, Ngamerni B (2007) Antimicrobial activity of the methanolic extract, fractions and compounds from the sterm bark of Irvingiagabonensis (Ixonanthaceae). J Ethnophamacol 114: 54-60.

22. Harris DJ (1996) A revision of the irvingiaceae in africa. Bulletin dujardin betarique natural de-belgigue 65: 143-196.

23. Ratklao S (2013) Screening of novel secondary metabolites from endophytic fungi by chemical library analysis. Osaka university knowledge archive.

24. Subbulakshmi GK, Thalavaipandian A, Bagyalakshmi VR, Rajendra A (2012) Bioactive endophytic fungal isolates of biota orientalis (L) Endl., Pinus excels wall and Thuja occidentalis L. Int J Adv Lif Sci 4: 1-7.

25. Cai YZ, Luo Q, Sun M, Corke H (2004) Antioxidant activity and phenolic compounds of 112 traditional Chinese medicinal plants associated with anticancer. Life Sci 74: 2157-2184.

26. Verma VC, Gond SK, Kumar A, Mishra A, Kharwar RN, et al. (2009) Endophytic actinomycetes from Azadirachta indica A. Juss.: isolation, diversity and anti-microbial activity. Microb Ecol 57: 749-756.

27. Castillo UF, Browne L, Strobel G, Hess WM, Ezra S, et al. (2007) Biologically active endophytic streptomycetes from nothofagus spp. and other plants in patagonia. Microb Ecol 53: 12-19.

28. Wiyakrutta S, Sriubolmas N, Panphut W, Thongon N, Danwiset-Kanjana $\mathrm{K}$, et al. (2004) Endophytic fungi with anti-microbial, anti-cancer and anti-malarial activities isolated from Thai medicinal plants. World J Microbiol Biotechnol 20: 265-272.

29. Corrado M, Katia F, Rodrigues KF (2004) Antimicrobial evaluation of fungal extracts produced by endophytic strains of Phomopsis sp. J Basic Microbiol 44: 157-160.

30. Li E, Jiang L, Guo L, Zhang H, Che Y (2008) Pestalachlorides A-C, antifungal metabolites from the plant endophytic fungus Pestalotiopsis adusta. Bioorg Med Chem.16: 7894-7899.

31. Ramasamy K, Lim SM, Bakar AB, Ismail N, Ismail MS, et al. (2010) Antimicrobial and cytotoxic activities of Malaysian endophytes. Phytothear Res 24: 640-643.

32. Siqueira VM, Conti R, Araujo JM, Souza-Motta CS (2011) Endophytic fungi from the medicinal plant Lippiasidoides Cham and their antimicrobial activity. Symbiosis 53: 89-95.

33. Kaaria P, Matiru V, Ndungu M (2012) Antimicrobial activities of secondary metabolites produced by endophytic bacteria from selected indigenous Kenyan plants. Afr J Microbiol Res 6: 7253-7258.

34. Jung R, Fish DN, Obritsch MD, Maclaren R (2005) Surveillance of multidrug resistant Pseudomonas aeroginosa in an urban tertiary-care teaching hospital. Pharmacotherapy 25: 1353-1364.

35. Gong LJ, Gou SH (2009) Endophytic fungi from Dracaena cambodiana and Aquilaria sinensis and their antimicrobial activity. Afr J Biotechnol 8: 731-736.

36. Kharwar RN, Verma SK, Mishra A, Gond SK, Sharma VK, et al. (2011) Assessment of diversity, distribution and antibacterial activity of endophtic fungi isolated from a medicinal plant Adenocalymma alliaceum Miers. Symbiosis 55: 39-46.

37. Denise O, Guimaraes S, Borges Y, Kawano H, Ribeiro H, et al. (2008) Biological activities from extracts of endophytic fungi isolated from Viguiera arenaria and Tithonia diversifolia. FEMS Immunol Med Microbiol 52: 134-144.

38. Foldes T, Banhegyi I, Herpai Z, Varga L, Szigeti J (2000) Isolation of Bacillus strains from the rhizosphere of cereals and in vitro screening for antagonism against phytopathogenic, food-borne pathogenic and spoilage micro-organisms. J Appl Microbiol 89: 840-846. 
Citation: Nwakanma C, Njoku EN, Pharamat T (2016) Antimicrobial Activity of Secondary Metabolites of Fungi Isolated from Leaves of Bush Mango. Next Generat Sequenc \& Applic 3: 135. doi:10.4172/2469-9853.1000135

Page 6 of 6

39. Mao S, Lee SJ, Hwangbo H, Kim YW, Park KH, et al. (2006) Isolation and characterization of antifungal substances from Burkholderia spp. Culture broth Curr Microbiol 53: 358-364.

40. Omura S (1992) Trends in the search for bioactive microbial metabolites. J Ind Microbiol 10: 135-136.

41. Ananda K, Sathish L, Pavithral N (2012) Antimicrobial and enzyme activity of endophytic fungi isolated from Tulsi. J Pharm Biomed Sci 16.
42. Thalavaipandian A, Arivudainambi US, Bagya L, Rajendran A (2011) Antimicrobial Potential of endophytic fungus Colletotrichum gloeosporioides associated with Madhuca longifolia L. Adv Appl Res 3: $1-7$. 